\title{
Miguel Maria Jardim: a constituição da trajetória de um professor-autor
}

\author{
Miguel Maria Jardim: the constitution of the trajectory of a teacher-author
}

\author{
Rosiane Morais Santos Feitosa ${ }^{1}$ \\ Moysés Gonçalves Siqueira Filho ${ }^{2}$
}

\section{Resumo}

Este artigo tem por objetivos delinear a trajetória de Miguel Maria Jardim, um professor primário e autor de Arithmetica Elementar, e apresentar a difusão/circulação de seu compêndio em território brasileiro. A partir da análise dos jornais que circularam no período de 1860 a 1925, sobretudo nos estados do Rio de Janeiro e de São Paulo, foi feita uma pesquisa histórico-documental, cujo resultado sinalizou: várias edições da Arithmetica Elementar; a circulação do compêndio por quase 20 anos em cinco estados brasileiros - Rio de Janeiro, Bahia, Alagoas, Pará e Espírito Santo -; e a presença do método sintético na edição de 1879.

Palavras-chave: Arithmetica Elementar; Miguel Maria Jardim; Jornais

\begin{abstract}
This article aims to [1] outline the trajectory of Miguel Maria Jardim, a primary teacher and author of Arithmetica Elementar; [2] to present the diffusion / circulation of its compendium in Brazilian territory. From a historical-documentary research, we used as a privileged source the newspapers that served in the period from 1860 to 1925, especially in the states of Rio de Janeiro and São Paulo. The analysis undertaken from the sources point out several issues of Arithmetica Elementar; the circulation of the compendium for almost 20 years in five Brazilian states - Rio de Janeiro, Bahia, Alagoas, Pará and Espírito Santo; the presence of the synthetic method in the 1879 edition.
\end{abstract}

Keywords: Arithmetic Elemental; Miguel Maria Jardim; Newspapers

\section{Considerações iniciais}

O presente artigo $^{3}$ objetiva delinear a constituição da trajetória de Miguel Maria Jardim e apresentar a difusão/circulação ${ }^{4}$ do compêndio Arithmetica Elementar, de sua

Submetido em: 15/12/2018 - Aceito em: 26/04/2019 - Publicado em: 26/04/2019.

${ }^{1}$ Mestra em Ensino na Educação Básica pela Universidade Federal do Espírito Santo. Professora de Matemática da Rede Estadual - Secretaria de Estado da Educação do Espírito Santo - SEDU. Membro do GHEMAT. Email: rosiane27@gmail.com

2 Doutor em Educação (Matemática) pela Universidade Estadual de Campinas. Professor do Departamento de Educação e Ciências Humanas e do Programa de Pós-Graduação em Ensino na Educação Básica da Universidade Federal do Espírito Santo, Brasil. Membro do GHEMAT. Email: siqueira.moyses@ gmail.com

${ }^{3}$ Trata de um recorte da pesquisa de mestrado intitulada "A aritmética na escola primária do Espírito Santo na década de 1870: percepções a partir da obra de Miguel Maria Jardim”.

4 Oliveira (2018) apresenta um estudo sobre o tema "circulação", no qual afirma que esta "só pode ser caracterizada se existir algo para ser difundido e, por consequência, recepcionado" (p. 4 e p. 14). Dessa forma levanta a seguinte questão: "como descrever a dinâmica da circulação de algo?" Pensando na circulação da Arithmetica Elementar, de Jardim, buscaremos apresentar a circulação, difundida a partir dos jornais impressos, Zetetiké, Campinas, SP, v.27, 2019, p.1-15 - e019016 
DOI: http://dx.doi.org/10.20396/zet.v27i0.8654287

autoria, adotado pela Instrução Pública do estado do Espírito Santo, na década de 1870, considerando os conteúdos e os métodos propostos pela legislação vigentes na época, a partir do que julgamos ser uma fonte privilegiada para identificar diferentes e variados elementos históricos para a elaboração de um personagem, os métodos e os recursos para o ensino de determinada rubrica, ou seja, os jornais. Para tanto, em busca das fontes, fizemos uma investigação no acervo da Hemeroteca Digital", empregando as palavras-chave "Miguel Maria Jardim" e "Arithmetica Elementar de Jardim". Por meio dessa pesquisa, identificamos 11 jornais ${ }^{6}$ que circularam, no período de 1860 a 1925, nos estados do Rio de Janeiro e São Paulo, os quais forneceram elementos para o nosso objeto de estudo.

Apesar da utilização dos jornais ainda ser algo recente nas pesquisas, de acordo com Farias (2014), nas últimas décadas têm se tornado um meio bastante importante "para o estudo da História da Educação e da Pedagogia, bem como para o estudo da História da Educação Matemática no Brasil, principalmente quando aborda um período ainda pouco investigado, como o século XIX” (p. 45).

Segundo Capelato (1988), os jornais, de publicação diária ou semanal, podem ser estudados desde os argumentos expressos em seus editoriais até os classificados e as propagandas, pois eles são

uma verdadeira mina de conhecimento: fonte de sua própria história e das situações mais diversas; meio de expressão de idéias e depósito de cultura. Nele encontramos dados sobre a sociedade, seus usos e costumes, informes sobre questões econômicas e políticas. (p. 21)

Por essas razões, aderimos ao estudo dos jornais, identificados na Hemeroteca Digital, e desta feita, localizamos algumas notícias, principalmente as veiculadas nos do Rio de Janeiro, as quais apontaram o livro Arithmetica Elementar ${ }^{7}$, de Miguel Maria Jardim, como tendo sido adotado pela instrução pública espírito-santense, no período de 1878 a 1895 . Naturalmente, ao iniciarmos a análise do referido livro, tendo como objetivo verificar como este refletira os conteúdos e os métodos propostos nas legislações vigentes na época, ocorreram-nos algumas questões: quem foi seu autor?; Qual sua formação?; Publicou outros livros?; A que público se destinava o Arithmetica Elementar?; Em que ano surgiu sua 1, ${ }^{\text {a }}$

existentes no final do século XIX e início do século XX, pois os meios de comunicação disponíveis e acessíveis em cada época e em cada contexto representam as dinâmicas de circulação de algo.

${ }^{5}$ A Hemeroteca Digital é um portal de periódicos nacionais que proporciona ampla consulta, pela internet, ao acervo de periódicos: jornais, revistas, anuários, boletins, etc. Por meio desse portal é possível, por exemplo, acessar jornais criados no país no ano de 1808 (BNDigital, 2018).

${ }^{6}$ Os jornais, identificados no estado do Rio de Janeiro, são: A Patria: folha da província do Rio de Janeiro (1856-1889); Correio Mercantil, e Instructivo, Politico Universal (1848-1868); Correio da Manhã (1920-1929); Diário do Rio de Janeiro (1860-1878); Gazeta de Notícias (1875-1956); O Globo (1874-1883); O Fluminense (1878-2016), os dois últimos de publicação diária, e A Instucção Publica: publicação hebdomadaria (18701889), jornal de publicação semanal, destinado aos professores do Rio de Janeiro, organizado por José Carlos Alambary Luz, ex-diretor da Escola Normal de Niterói (1868). E no estado de São Paulo: Correio Paulistano (1850-1969); Diário de São Paulo (1860-1879) e Gazeta de Campinas: publicação diária (1870-1889), os dois últimos de publicação diária.

${ }^{7}$ Um exemplar foi localizado na Biblioteca Nacional de Portugal/Lisboa. 
DOI: http://dx.doi.org/10.20396/zet.v27i0.8654287

edição?; Por qual editora? Com qual organização? Quantas edições posteriores houve? Circulou em quais estados?; Como ocorreu seu processo de difusão?

\section{Miguel Maria Jardim: a trajetória de um professor-autor}

Nascido em 02 de dezembro de 1841, em Portugal, chegou ao Brasil em 26 de janeiro de 1857, na cidade de Campos (RJ). Entretanto, fixou moradia na Corte somente a partir de 1860. Após cinco anos, mais precisamente, em 17 de maio de 1865, com 24 anos, naturalizou-se brasileiro (Figura 1).

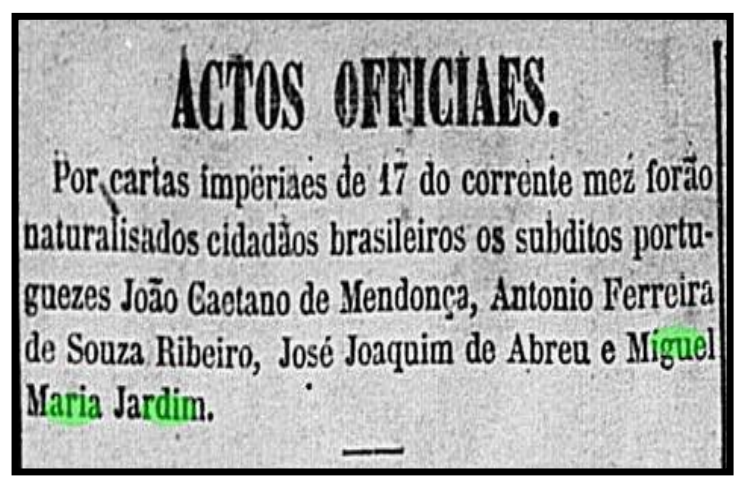

Figura 1 - Actos Officiaes - Naturalização de Portugueses - 1865

Fonte: Correio Mercantil, Rio de Janeiro, 20 de maio de 1865 (Hemeroteca Digital)

Jardim frequentou a Escola Normal de Niterói, na província do Rio de Janeiro, no período de 1865 a 1866, instituição na qual foi qualificado para exercer a função do magistério. A Escola Normal de Niterói foi a primeira escola normal do Brasil, criada em 1835, na cidade de Niterói, e extinta, 14 anos depois, por Couto Ferraz, presidente da província do Rio de Janeiro, "por considerá-la onerosa e ineficiente na formação de professores", Durante o período em que esteve desativada, "as pessoas habilitavam-se professores à medida que atuavam como ajudantes do regente de classe, por meio da prática de ensino" (Siqueira Filho, 2016, p. 369). Anos mais tarde, em 1862, foi reaberta em presença de S. M. o Imperador (Feitosa, 2018).

Em sua segunda fase, foi caracterizada, segundo Villela (2002), como um modelo profissional de formação de professores para a escola primária, tendo a sua pedagogia como um dos seus diferenciais. Ali os normalistas aprenderiam a ensinar ou mesmo a buscar suas próprias vocações. Esse novo momento vivido pela Escola Normal de Niterói foi seguido de mudanças, entre elas, a entrada das mulheres nas salas de aula da escola normal.

Foi, portanto, nesse cenário, apresentado pela Escola Normal da província do Rio de Janeiro, onde fora "pensionista" e considerado um "alumno mestre" (Rio de Janeiro, 1866a, p.3), que Jardim realizou seus estudos para obter uma formação profissional que o habilitasse a exercer a função de professor primário. Assim, após ter sido aprovado, plenamente, pela banca examinadora, em gramática; pedagogia; aritmética; álgebra; geometria; historia geral e do Brasil (Rio de Janeiro, 1866b), concluiu seu Curso em dezembro de 1866. No ano 
DOI: http://dx.doi.org/10.20396/zet.v27i0.8654287

seguinte $^{8}$, iniciou sua carreira no magistério público, no qual atuou por 13 anos, 5 meses e 15 dias (Rio de Janeiro, 1880).

No Quadro 1 estão listadas as escolas e suas respectivas cidades em que o professor trabalhou no Rio de Janeiro. Em maio de 1873, foi concedido a Jardim o título de capacidade profissional que o habilitava a "ensinar instrução primária e sistema métrico" (Brasil, 1874, p. 89).

Quadro 1 - Locais em que M. M. Jardim atuou como professor na Província do Rio de Janeiro - 1867 a 1880.

\begin{tabular}{|c|c|l|}
\hline Ano & Cidade & \multicolumn{1}{c|}{ Escola } \\
\hline $1867-1868$ & Nova Friburgo & Freguezia de N. Senhora da Conceição de Paquequer. \\
\hline $1869^{9}-1872^{10}$ & Niterói & $1^{\circ}$ Distrito - Ponta da Arêa \\
\hline $1873-1880$ & Niterói & $2^{\circ}$ Distrito - Escola do sexo masculino - São Domingos. \\
\hline
\end{tabular}

Fonte: Almanak Administrativo, Mercantil e Industrial do Rio de Janeiro (1867-1880) - Hemeroteca Digital

Por questões de doença, o professor precisou ausentar-se para cuidar de sua saúde. Assim, em 1878, requereu, junto ao governo, licença de um ano, com todos os vencimentos. A concessão de seu pedido foi-lhe dada por meio do Decreto n. ${ }^{\circ} 2.382$, de 9 de outubro, o qual afirmava que Jardim poderia se cuidar onde lhe bem conviesse (Rio de Janeiro, 1878, p. 162). Miguel M. Jardim, esposa e quatro filhos embarcaram no dia 18 de dezembro de 1878 , no vapor inglez Maskelyne, para Lisboa, conforme noticiado pelo jornal O Cruzeiro, no dia seguinte.

Decorrido o tempo de licença, o jornal O Fluminense, em 14 de dezembro de 1879 , anunciou seu retorno ao Brasil:

O distincto professor Miguel Maria Jardim, que se achava na Europa para onde tinha partido, licenciado pelo governo, afim de tratar-se d'um incomodo de saude, já se acha entre nós.

Felicitamos por isso ao bairro de S. Domingos, onde se acha a escola publica de que S. S. é digno professor (Rio de Janeiro, 1879, p. 3).

\footnotetext{
${ }^{8}$ Nomeado professor efetivo da província do Rio de Janeiro, atuou como professor primário da freguesia de Nossa Senhora de Parquequer, em Nova Friburgo (Rio de Janeiro, 1867, p. 3). Após trabalhar em Parquequer, durante dois anos, requereu sua transferência e, em dezembro de 1868, por ato de governo, sua remoção foi autorizada (Rio de Janeiro, 1868). Em 1869, na cidade de Niterói, capital da província do Rio de Janeiro à época, passou a exercer a função de professor primário no 1..$^{\circ}$ Distrito - Ponta da Areia. Em 1872, requereu outra transferência, assumindo, em 1873, a regência da escola do sexo masculino do 2..$^{\circ}$ Distrito - São Domingos (Rio de Janeiro, 1872b).

${ }^{9}$ Em 1869, casou-se com Josefina Maria de Souza, com quem teve 11 filhos, sendo 6 homens e 5 mulheres. São eles: Theodoro, Cornelio, Annibal, Juvenal, Balthazar, Cezar, Agueda, Clara, Leocádia, Olindina e Laura. Como pai, Jardim passou pela triste experiência de sepultar 6 filhos: Agueda e Cezar, quando ainda eram pequenos; Clara, aos 15 anos de idade; o capitão Annibal Jardim, que comandava o 1. ${ }^{\circ}$ regimento de artilharia da Guarda Nacional; o capitão de corveta Juvenal; o professor Balthazar. Sua esposa, Josefina Maria de Souza Lordello Jardim atuava como professora pública na cidade de Niterói em 1895, ano em que veio a falecer, "deixando 9 filhos, dos quais 7 ainda menores" (Rio de Janeiro, 1895a, p.2).

${ }^{10}$ Em 17 de junho, mediante ato de governo, publicado no jornal A Patria, em 23 de junho, Jardim foi considerado professor vitalício (Rio de Janeiro, 1872a).
} 
DOI: http://dx.doi.org/10.20396/zet.v27i0.8654287

Posteriormente, foi eleito presidente do Instituto Pedagógico ${ }^{11}$. O fato de ser nomeado para esse cargo indica que era respeitado pelos colegas de profissão que viam em sua atuação qualidades específicas de um profissional engajado. Ressaltamos, ainda, que a posição ocupada por Jardim, dentro dessa associação de professores, não pode ser vista apenas por mérito, mas também pelo modo como ele se articulava à "rede de sociabilidade", tecida a partir da posição de cada indivíduo no espaço social.

Transcorridos mais de 13 anos de atuação na instrução pública primária da província do Rio de Janeiro, Jardim aposentou-se em 1880. Conforme a legislação do estado do Espírito Santo, por exemplo, na época tinha direito à jubilação com ordenado integral, os professores que completassem 25 anos de serviço no magistério (Espírito Santo, 1877). Assumindo que o estado do Rio de Janeiro seguia a mesma orientação, vemos que esta regra não se aplicou a Jardim, pois os 13 anos trabalhados incluem a licença que tirou para cuidar da saúde durante todo o ano de 1879. Logo, o que teria levado a aposentar-se tão cedo? Bem, a mesma legislação afirmava que os professores que tivessem mais de 10 anos de bons serviços e ficassem impossibilitados de continuar na regência de suas cadeiras, poderiam obter suas jubilações com ordenado proporcional ao tempo que tivessem de exercícios (Espírito Santo, 1877), o que, possivelmente, pode explicar a aposentadoria prematura de $\operatorname{Jardim}^{12}$.

Como era dono de alguns imóveis na Rua Marechal Deodoro, inclusive, uma livraria intitulada, "Livraria Miguel Maria Jardim", sua aposentadoria lhe permitiu trabalhar como comerciante, vindo a ser ora presidente, ora vice-presidente da Associação Comercial do Rio de Janeiro (Rio de Janeiro, 1917, p.1501). Entretanto, em 1885, voltou a atuar na instrução pública exercendo a função de inspetor e, dez anos depois, a de delegado literário ${ }^{13}$, ambas na cidade de Niterói/RJ (Rio de Janeiro, 1885;1895b). Ao exercer tais funções, Jardim já era autor de seis compêndios, Taboada Metrica; Tabella Metrica Commercial; Exercícios de contar adaptados a classe dos principiantes das escolas primarias; Arithmetica Elementar, Cathecismo da Doutrina Christã e Syllabario Escolar, logo a posição de inspetor e delegado ter-lhe-ia sido muito conveniente. Todavia, ressaltamos que a Arithmetica Elementar, de sua autoria, fora adotada pelo Conselho de Instrução Pública da Província do Rio de Janeiro, anos antes de exercer tais cargos, como veremos mais adiante.

\footnotetext{
${ }^{11}$ Jardim foi e um dos fundadores do Instituto Pedagógico, no qual exerceu também a função de 1 . $^{\circ}$ secretário. O Instituto, com sede em Niterói, quando foi fundado, em 1873, contava com 156 professores filiados. Era uma sociedade formada por professores públicos, da Província do Rio de Janeiro, tendo, como objetivo precípuo, a instrução e a beneficência de seus membros (Rio de Janeiro, 1873b).

12 “foi fixado em 538\$330 o vencimento anual do professor jubilado Miguel Maria Jardim, correspondendo a 13 annos, 5 mezes e 15 dias de serviços" (Rio Janeiro, 1880, p.3). A notícia veiculada no Jornal O Fluminense indica que o valor pago a Jardim era proporcional ao tempo trabalhado, corroborando as ideias deste artigo.

13 O Estado era divido em distritos escolares, e o ensino nesses distritos era fiscalizado por um delegado literário. Dentre as várias atribuições do cargo, destacamos: ser responsável por inspecionar as aulas de seu distrito; suspender professores que não seguiam as regras da moral; dar posse aos professores; propor a nomeação e a demissão dos fiscais escolares.
} 
DOI: http://dx.doi.org/10.20396/zet.v27i0.8654287

O professor, comerciante e livreiro, era uma figura ilustre da sociedade fluminense, com um largo círculo de relações. Sua livraria era o local escolhido para reunir-se com os amigos. A sua família era composta por pessoas respeitadas na sociedade, pois seus filhos e genros ocupavam cargos de grande destaque (Rio de Janeiro, 1925b).

No dia em que completou 84 anos, o jornal $O$ Fluminense destacou que o professor "foi um dos que escreveram para o nosso primeiro numero e ainda hoje nos honra com seus trabalhos, que sempre foram em pról das causas nobres e justas" (Rio de Janeiro, 1925a, p. 1).

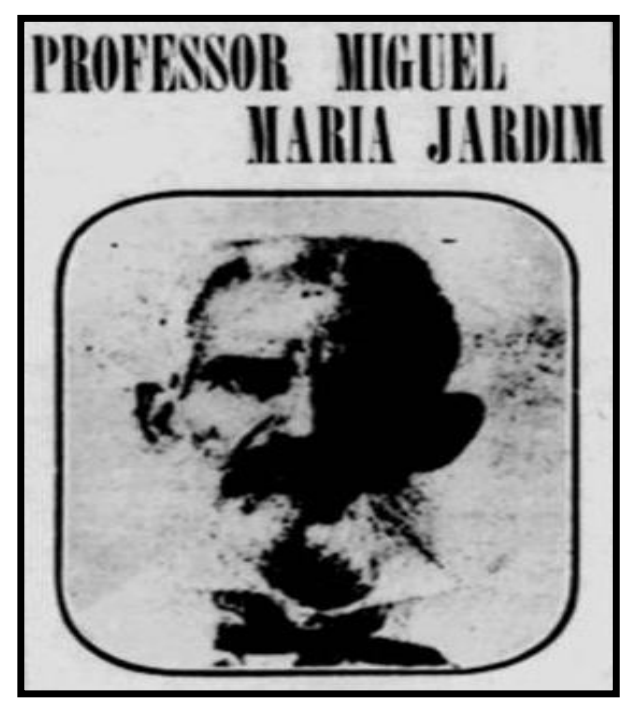

Figura 2 - Professor Miguel Maria Jardim - 1925 - Rio de Janeiro Fonte: $O$ Fluminense, 02 de dez. 1925b (Hemeroteca Digital)

Dois dias depois, já enfermo e acamado, faleceu em 4 de dezembro de 1925, como se pode constatar no excerto do referido jornal:

Falleceu hontem em Nictheroy com 84 anos de edade o sr. Miguel Maria Jardim, professor aposentado do Estado do Rio. Contava o professor Jardim um largo circulo de relações, sendo a "sua Livraria ponto de reunião de seus numerosos amigos". Collaborou no "Fluminense" desde o primeiro numero desse jornal. Trabalhou com lucidez até recolher-se ha poucos dias enfermo ao leito.

Deixa dois filhos: o capitão de fragata Theodoro Jardim e o coronel Cornelio Jardim, do alto commercio desta praça, e ter filhas Olindina, casada com o professor Erasmo Braga; Laura, casada com o Sr. Claudomiro Pereira da Silva, e Leocadia, casada com o dr. Victor da Cunha, procurador geral da Fazenda do Estado do Rio.

O enterro effectuar-se-á hoje, ás 3 horas, saindo da rua Visconde do Rio Branco n. 739, na visinha capital [ênfases adicionadas]. (Rio de Janeiro, 1925b, p. 5)

Alguns dos registros dos fatos, sobre a trajetória de Miguel Maria Jardim, obtidos a partir dos jornais que circularam no Rio de Janeiro, nos permitiram identificar as diferentes posições por ele ocupadas, o que lhe conferiu ser estimado, não só pelos professores do seu estado, mas também pelos de outros, como os da capital paulista que o diplomaram como “Sócio Honorário do Instituto Pedagógico de São Paulo” (Rio de Janeiro, 1877, p. 79). 


\section{Arithmetica Elementar, de Miguel Maria Jardim: edições e circulação}

A primeira edição desse compêndio foi publicada na segunda metade do século XIX, precisamente no ano de 1872, tendo a aprovação da Escola Normal da província do Rio de Janeiro, conforme noticiado pela imprensa: "Arithmetica Elementar. - Com este titulo acaba de publicar um compendio, que foi aprovado pela escola normal da província do Rio de Janeiro, o Sr. professor publico Miguel Maria Jardim” (Rio de Janeiro, 1872d, p. 3).

Já eram passados seis anos desde que concluíra seus estudos e cinco que exercia a carreira pública no magistério. Sobre sua atuação profissional, o jornal A Instrucção Publica: Publicação Hebdomadaria, do Rio de Janeiro, trouxe, em uma de suas páginas, em 21 de julho, do ano em voga que "O Sr. Miguel Maria Jardim, professor publico de uma das escolas da capital da província do Rio de Janeiro, ... foi um dos melhores alumnos da Escola Normal, e hoje faz honra à numerosa classe a que pertence" (Rio de Janeiro, 1872c, p. 10).

O fato de o compêndio de Jardim ter sido aprovado pela Escola Normal, da qual fora ex-aluno-mestre, demonstra que ele estava de acordo com as diretrizes educacionais da época, tais como eram interpretadas pelos professores e, segundo Bittencourt (2004, p.479), "o autor de uma obra didática deve ser, em princípio, um seguidor dos programas oficiais propostos pela política educacional”. A Escola Normal era uma instituição de grande relevância educacional (Villela, 2008), assim, ao validar seu livro, valorizou suas ideias e, muito provavelmente, estimulou sua aceitação pelo público, pois já se anunciava uma 2. edição, a 300 réis, n'O Diário do Rio de Janeiro, enquanto a Gazeta de Campinas: publicação diária, um periódico que circulou na província de São Paulo, no período de 1869 a 1875 , assim se posicionava:

"Arithmetica Elementar" [ênfase no original] - O sr. Miguel Maria Jardim, professor
publico da província do Rio de Janeiro, acaba de compor um compendio de
arithmetica elementar que nos parece muito util e digno de todo o acolhimento
publico principalmente para ser lido nas escholas primaria, pois além das materias
geraes indicadas no titulo, traz este interessante opúsculo noções muito aproveitáveis
sobre o systhmea métrico, assunpto de tanta actualidade agora para todos. (São Paulo,
1873b, p. 2)

Além desses dois, outro periódico diário paulista, o Diário de São Paulo, fez a seguinte referência:

"Arithmetica Elementar" [ênfase no original] - Recebemos e agradecemos um exemplar desta obra que nos foi remetida pelo autor, o sr. Miguel Maria Jardim, intelligente professor publico na província do Rio de Janeiro. É um trabalho singelo e ao alcance da mais tenra intelligencia: tal é a clareza com que se acha escripta a sua Arithmetica Elementar. (São Paulo, 1873a, p. 3)

Dois anos depois, em 1875, identificamos no mesmo periódico, a notícia de que Jardim solicitava o parecer do Inspetor Geral da Instrução e professor da Escola Normal de São Paulo, após encaminhar-lhe alguns exemplares de seu livro. 
DOI: http://dx.doi.org/10.20396/zet.v27i0.8654287

Bittencourt (1993) afirma que "quando autores se encarregavam da publicação de seus próprios textos, tinham o hábito de enviar um exemplar aos jornais, sendo que, várias vezes, os elogios jornalísticos eram incorporados nas edições sequenciais dos livros" (p.114). Com Jardim não foi diferente, pois se valeu dessa ação para, além da divulgação em diferentes províncias, agregar os elogios tecidos pelos redatores dos jornais relativos tanto à qualidade do livro quanto ao seu desempenho profissional.

Nesse mesmo sentido, Miorim (2014) enfatiza que "anúncios em jornais, declaração de personalidades conhecidas nas páginas iniciais dos livros, artigos sobre o autor e livro em periódicos e em revistas, catálogos, etc.” (p. 141) tornaram-se uma prática com o intuito de convencer professores e outros profissionais da educação da adequação da produção que se intentava difundir e, dessa forma, ratificar, de acordo com Oliveira (2018) que os meios de comunicação "injetam certo impacto na recepção e apropriação da mensagem propagada" (p. 27), como podemos observar na nota do jornal $O$ Globo:

Recebemos um exemplar da $3^{\text {a }}$ edição "Arithmetica Elementar" [ênfase no original] do Sr. M. M. Jardim, professor publico da província do Rio de Janeiro. Os resultados que na pratica se têm colhido deste excellente compendio, justificam hoje plenamente a adopção delle pelo conselho de intrucção publica da província para o uso das suas escolas. É sempre com satisfação que vemos medrar entre nós as obras de ensino, principalmente quando, como esta, têm verdadeiro valor. (Rio de Janeiro, 1875, p. 3)

Localizamos um exemplar publicado, em 1879, pela Typographia da Reforma/RJ, na Biblioteca Nacional de Portugal - BNP, com sede em Lisboa. Certamente, Jardim o tenha doado quando se licenciou para cuidar de sua saúde e foi para Portugal. Os vestígios dessa informação podem ser observados em sua folha de rosto.

De pronto, sua capa denota que a obra foi "adoptada pelos Conselhos de Instrucção Publica das províncias do Rio de Janeiro, Bahia, Alagôas, Pará e "Espirito Santo" [ênfase adicionada], para uso das escolas das mesmas províncias" (Jardim, 1879), o que implica uma significativa circulação pelas escolas primárias espalhadas ao longo do território brasileiro.

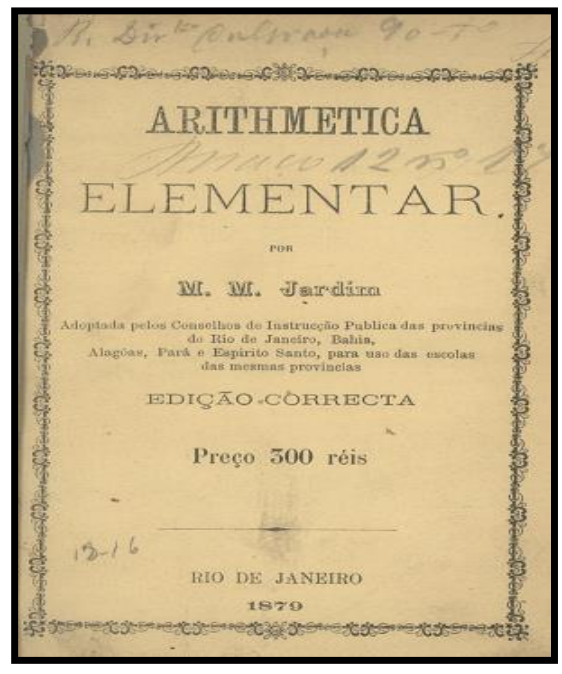

Figura 3 - Capa da Arithmetica Elementar de Jardim - 1879

Fonte: Acervo da Biblioteca Nacional de Portugal, 2018 
DOI: http://dx.doi.org/10.20396/zet.v27i0.8654287

Disponível para venda nas livrarias das províncias de São Paulo, Alagoas, Pará, Bahia e Rio de Janeiro, como já dito anteriormente, a de Niterói pertencia ao autor, e lojas de papel da Corte (Jardim, 1879). Constatamos, também, sua circulação nas províncias do Amazonas, São Paulo, Maranhão e Minas Gerais.

Por exemplo, em São Paulo, no ano de 1877, o Diário de São Paulo, em 8 de março, noticiou um pedido, assinado por "muitos professores", dirigido ao governo, para que houvesse a adoção do compêndio de Jardim para o ensino das escolas primárias paulistas:

Pedimos ao sr. dr. inspector-geral que proponha ao exm. governo a adopção da "Arithmetica Jardim" [ênfase adicionada] para o ensino das escolas primarias da província. Sabemos que essa obra obteve parecer favoravel dos illustrados drs. Americo de Abreu, Melchiades e Freire. Muitos professores ${ }^{14}$. (São Paulo, 1877, p. 2)

Tal solicitação foi publicada durante cinco edições seguidas no referido jornal. Conforme Chartier (2002), "as representações do mundo social..., embora aspirem a universalidade de um diagnóstico fundado na razão, são sempre determinadas pelos interesses de um grupo que as forjam” (p. 17), estabelecendo, dessa forma, os modos de ver daqueles que falam em consonância com o lugar de onde falam. Americo de Abreu, Melchiades e Freire atuavam naquele ano, respectivamente, como diretor, professor e avaliador de exames finais na Escola Normal paulista e eram tidos por aqueles professores como referências no ensino.

Assim como acontecera no Rio de Janeiro, a Escola Normal de São Paulo validou a obra de Miguel Maria Jardim, o que atestou sua adoção nas escolas primárias pelo governo paulista.

Em relação à materialidade, a Arithmetica Elementar (1879) possui 128 páginas, de dimensões $13 \mathrm{~cm}$ de largura por $19 \mathrm{~cm}$ de comprimento; sua capa e o corpo foram confeccionados em papel à base de polpa de madeira de processo de fabricação mecânica (BNP, 2018). Na folha de rosto são reproduzidas as mesmas informações que constam na capa com a inserção do nome da editora e seu endereço. A obra não apresenta prefácio. Quanto ao número de edições, constatamos terem havido, após a publicação de 1879, novas tiragens, como veremos a seguir:

- 1882, São Paulo, Correio Paulistano (Figura 4):

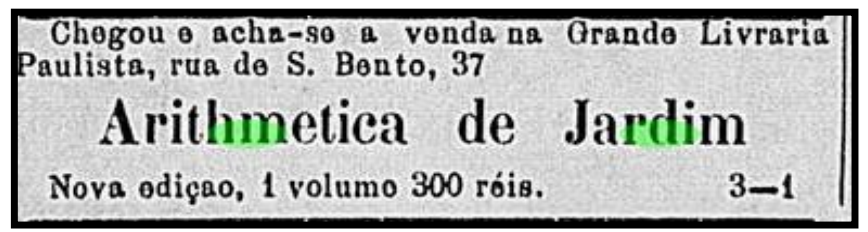

Figura 4 - Nova edição da Arithmetica de Jardim - 1882

Fonte: Correio Paulistano, 11 de agosto de 1882 (Hemeroteca Digital)

\footnotetext{
${ }^{14}$ Forma como era assinada a notícia veiculada no jornal.
} 
DOI: http://dx.doi.org/10.20396/zet.v27i0.8654287

- 1891, Maranhão, A Cruzada. Essa nova edição apresentava as moedas nacionais utilizadas no início do período republicano (Maranhão, 1891, p.1);

- 1899, Rio de Janeiro, O Fluminense, 07 de junho:

O incansável professor Miguel Maria Jardim acaba de publicar uma nova edição de sua Arithmetica Elementar. As sucessivas edições que tem tido esse bem elaborado compendio e a sua adoção em vários Estado da Republica fazem o seu completo elogio. (Rio de Janeiro, 1899b, p.1)

Em 11 de fevereiro de 1899, o mesmo veículo publicou um artigo intitulado "Um Livro Didactico”, no qual seu autor, identificado apenas pela letra J., fez referência à obra de Jardim desta maneira:

Queremos fallar de um recente trabalho do operoso professor jubilado, o sr. Miguel Maria Jardim, muito conhecido no nosso mundo pedagogico, um homem que tem levado a vida a se occupar com as cousas do ensino no territorio fluminense, ha muitos annos, e hoje o introductor da livraria e papelaria entre nós. Intitula-se o novo compendio - Arithmetica Elementar ( $2^{\circ}$ anno) e pode ser admitido com vantagens nas classes primarias em geral, nas adiantadas e nos cursos secundários mesmo, si atendermos a que, antes da abstração mathematica, o estudante precisa conhecer a materia praticamente, para com segurança poder prosseguir. O livro não é volumoso, contém apenas 164 paginas e, contudo, nellas encerra tudo quanto se pode exigir sobre arithmetica, - tal é a synthese em que, com a autoridade da experiência que tem o autor a encerrou.

Desde as simples taboadas até ás regras de tres e suas numerosas applicações, os systemas de numeração, o trabalho abrange toda a arithmetica, incluindo muitos esclarecimentos interessantes sempre e que os outros compendios não contêm. Alem disto, a cada ponto exposto com clareza e concisão seguem-se exercícios, e no capitulo referente ao systema metrico decimal ha os modelos dos differentes pesos e medidas, de moedas nacionaes e estrangeiras, etc. Por outro lado e ao passo que o methodo seguido adapta-se bem ás nossas necessidades escolares, a nova "Arithmetica Elementar" reúne a condição de modicidade no preço, circunstancia que não é para desprezar, porque todos sabem quantos exemplares de compendios o alumno estraga para estudar a materia em gráo rudimentar. "Poderíamos aduzir algumas observações sobre diversos pontos do livro, em contrario à opinião do autor; mas serviriam ellas somente para patentearem o nosso modo de ver e não destruiriam de forma nenhuma a excellencia do trabalho", que certamente veio prestar um bom serviço à didactica, cujos elementos, - os processos, - dependem do professor, e o sr. Miguel Maria Jardim, como outrora, ainda é um professor, às voltas sempre com os livros (sic) e com os colegas, a quem serve. A "Arithmetica Elementar" já esta adoptada em muitos Estados da União Brazileira pelos competentes conselhos de intrucção, como os do nosso, da Bahia, das Alagôas, do Pará e do Espírito-Santo [ênfases no original]. (Rio de Janeiro, 1899a, p.1)

J., sutilmente, critica não constar a apresentação dos processos que conduzem as lições que compõem o livro de Jardim, entretanto essa ausência não desqualificaria o compêndio, uma vez que isso dependeria do professor que o adotasse. Por outro lado, o parecer de J. nos traz algumas constatações: a adoção do Arithmetica Elementar pelos estados do Rio de Janeiro, Bahia, Alagoas e Espírito Santo por, no mínimo, 20 anos - 1879 a 1899; um acréscimo de 36 páginas, se comparado ao da edição de 1879. Não está explícito qual o 
DOI: http://dx.doi.org/10.20396/zet.v27i0.8654287

método adotado por Jardim na nova edição, entretanto ele enfatiza se adaptar às necessidades escolares da época.

A esse respeito, com o advento da República, Benjamin Constant, professor de matemática na Escola Militar e, posteriormente, ministro da Instrução Pública, por meio do Decreto n. ${ }^{\circ} 981$, de 8 de novembro de 1890, idealizou uma reforma educacional em âmbito nacional, a qual, entretanto, somente foi efetivada na capital federal e não chegou a ser, totalmente, posta em prática. De acordo com Legros e Siqueira Filho (2016),

A partir de então, o ensino primário, livre, gratuito e laico seria ministrado em escolas públicas de duas categorias: $1 .^{\circ}$ e $2 .^{\circ}$ graus, ... O ensino do $10^{\circ}$ grau abrangeria três cursos ... os quais deveriam ser contemplados pela aplicação do methodo intuitivo. (p.18).

Logo, como as escolas primárias deveriam seguir o método previsto na Reforma empreendida por Benjamin Constant, e diante da alegação de que a obra de Jardim atendia às necessidades escolares, podemos conjecturar que o método seguido por esse autor, na nova edição da Arithmetica Elementar, muito provavelmente, tenha sido o intuitivo, o que pode explicar o acréscimo das novas páginas para atender à nova legislação ${ }^{15}$.

- 1907, Rio de Janeiro, Gazeta de Notícias, 06 de setembro:

O Sr. almirante ministro da marinha, tendo em vista o parecer da comissão incumbida de pronunciar-se sobre o mérito das "Arithmeticas Elementares" [ênfase no original] do $1^{\circ}$ e $2^{\circ}$ annos, do professor Miguel Maria Jardim, approvou e mandou adopta-las nas escolas de aprendizes marinheiros e profissionais. (Rio de Janeiro, 1907, p. 2)

O noticiário se refere ao almirante Alexandrino Faria de Alencar, nomeado Ministro da Marinha do Brasil em 1906, por Afonso Augusto Pena, após assumir a presidência do Brasil. Alencar, por meio do Decreto n. ${ }^{\circ}$ 6.582, de $1^{\circ}$ de agosto de 1907, reformulou o ensino nas Escolas de Aprendizes Marinheiros, as quais passaram a ser divididas em duas categorias: Escolas Primárias ou de $1 .^{\circ}$ grau; Escolas Modelos ou de 2. ${ }^{\circ}$ grau, como descritas em seus $\operatorname{artigos} 5 .^{\circ}$ e $6 .^{\circ}$ :

Art. 5. . . As escolas-modelos serão estabelecidas nos Estados do Rio Grande do Norte, Bahia, Capital Federal e Rio Grande do Sul.

Art. 6. ${ }^{\circ}$. As escolas primarias serão estabelecidas nos Estados marítimos da Republica, não mencionados no artigo anterior, e nos Estados do Amazonas e de Matto Grosso (Decreto 6.582/1907).

Isto posto, a Arithmetica Elementar perfez, em 1907, uma circulação em 18 estados brasileiros: Alagoas, Amazonas, Bahia, Ceará, Espírito Santo, Maranhão, Mato Grosso, Pará, Paraná, Paraíba, Pernambuco, Piauí, Rio de Janeiro, Rio Grande do Norte, Rio Grande do Sul, Santa Catarina, São Paulo e Sergipe.

\footnotetext{
15 Jardim estruturou a sua Arithmetica Elementar (1879), segundo o método sintético, ou seja, a ordenação dos conteúdos de aritmética seguia a marcha das partes para o todo. Buscamos indícios do método intuitivosintético, no entanto, a edição de 1879, praticamente não apresenta gravuras, elemento de grande importância no processo intuitivo (Feitosa, 2018). Possivelmente, para atender o método intuitivo, na edição de 1899 foram inseridas figuras o que pode explicar o acréscimo de páginas.
} 


\section{Considerações finais}

DOI: http://dx.doi.org/10.20396/zet.v27i0.8654287

Ao admitirmos os jornais como uma rica fonte de extração de elementos históricos ou um instrumento catalisador de notícias, ora de um anúncio, ora de um comentário sobre a obra ou o autor e, ao analisarmos alguns deles - um conjunto composto de 11 jornais, sendo que 8 deles circularam no Rio de Janeiro e três em São Paulo - com o objetivo precípuo de delinear a constituição da trajetória de Miguel Maria Jardim e apresentar a difusão/circulação do compêndio Arithmetica Elementar, no período de 1860 a 1925, foi-nos possível conhecer os variados campos em que o autor-professor atuou, tais como, ex-aluno da Escola Normal de Niterói; professor primário da província do Rio de Janeiro; comerciante; livreiro; autor de livros; inspetor; delegado literário.

Foi pessoa de renome no seu tempo, exercendo grande influência na sociedade do Rio de Janeiro. Construiu um legado no exercício de suas atividades docentes na escola da freguesia de Nossa Senhora de Parquequer, em Nova Friburgo; nas escolas de Ponta de Areia e de São Domingos, ambas na cidade de Niterói; e na direção do Instituto Pedagógico do Rio de Janeiro.

Suas produções, assumidamente didáticas, lhe permitiram tratar sobre Taboada Metrica; Tabella Metrica Commercial; Exercícios de contar adaptados a classe dos principiantes das escolas primarias; Arithmetica Elementar. Além dessas quatro obras, publicou, também, Cathecismo da Doutrina Christã e Syllabario Escolar.

O compêndio Arithmetica Elementar circulou por, pelo menos, três décadas e meia (1872-1907) em território brasileiro, o que denota seu sucesso editorial. Muito provavelmente esse longo período de triunfo seja devido, entre outras possibilidades, aos pareceres positivos e enaltecedores emitidos por editores de jornais; por profissionais da Instrução Pública, de instituições como a Escola Normal, o que contribuiu para que fosse utilizado por alunos e professores de escolas primárias localizadas em 18 estados brasileiros.

\section{Referências}

Bittencourt, C. M. F. (1993). Livro didático e conhecimento histórico: uma história do saber escolar. Tese de Doutorado em História, Faculdade de Filosofia, Letras e Ciências Humanas da Universidade de São Paulo, São Paulo.

Bittencourt, C. M. F. (2004). Em foco: história, produção e memória do livro didático. Educação e Pesquisa, 30(3), 471-473.

BNDigital. Hemeroteca Digital. 2018. Retirado em 25 de fevereiro, 2018, de <http://bndigital.bn.gov.br/hemeroteca-digital/>.

Brasil (Ministério do Império). (1874). Relatório apresentado ao Ilmo. e Exm. Sr. Conselheiro João Alfredo Corrêa de Oliveira, ministro e secretario d'estado dos negócios do Imperio. Apresentado pelo Conselheiro da Inspectoria Geral da Instrucção Primaria e Secundaria, Dr. Antonio Felix Martins, em 18 de abril de 1874. Rio de Janeiro: Typographia Cinco de Março.

Capelato, M. H. R. (1988). Imprensa e história do Brasil. São Paulo: Contexto/Edusp. 
DOI: http://dx.doi.org/10.20396/zet.v27i0.8654287

Chartier, R. (2002). A história cultural - entre práticas e representações. Lisboa: Difel.

Decreto $n^{o} .6 .582$ de $1^{\circ}$ de agosto de 1907. (1907). Dá regulamento às Escolas de Aprendizes Marinheiros. Retirado em 01 de dezembro, 2018, de http://www2.camara.leg.br/legin/fed/decret/1900-1909/decreto-6582-1-agosto-1907514091-publicacaooriginal-1-pe.html.

Espírito Santo (Estado). (1877, dezembro 22). Regulamento de 17 de dezembro de 1877. $O$ Espírito-Santense, VII(153). Retirado em 16 de maior, 2018, 2018, de https://bndigital.bn.br/hemeroteca-digital/.

Farias, K. S. C. S. (2014). Jornais e revistas da instrução pública: luz pedagógica para as práticas de Aritmética na formação de professores da Escola Normal da Província do Rio de Janeiro. In A. Brito, K. Farias \& M. A. Miorim (Orgs.), Pesquisas históricas em jornais e revistas: produções do HIFEM (pp. 21-47). São Paulo: Livraria da Física.

Feitosa, R. M. S. (2018). A aritmética na escola primária do Espírito Santo na década de 1870: percepções a partir da obra de Miguel Maria Jardim. Dissertação de Mestrado em Ensino na Educação Básica, Universidade Federal do Espírito Santo, São Mateus.

Jardim, M. M. (1879). Arithmetica Elementar. Rio de Janeiro: Typographia da Reforma.

Legros, V., \& Siqueira Filho, M. G. (2016). A Arithmética e o Método Intuitivo nos manuais escolares do ensino primário (médio e superior/complementar) no Brasil e na França no final do século XIX e início do Século XX. Perspectiva, 34(1), 15-40.

Maranhão (Estado). (1891, janeiro 23). Nova Arithmetica de Jardim publicada em 1891. A Cruzada. II(85). Retirado em 02 de maio, 2018, de https://bndigital.bn.br/hemerotecadigital/.

Miorim, M. A. (2014). Divulgando livros didáticos de matemática: revistas de editoras brasileiras nas décadas de 1950 a 1970. In A. Brito, K. Farias, \& M. A. Miorim (Orgs.), Pesquisas históricas em jornais e revistas: produções do HIFEM (pp. 21-47). São Paulo: Livraria da Física.

Oliveira, M. A. (2018). Circulação - Cadernos de Trabalho II. São Paulo: Livraria da Física.

Rio de Janeiro (Estado). (1865, maio 20). Miguel M. Jardim naturalizado brasileiro. Correio Mercantil, XXII(138). Retirado em 06 de fevereiro, 2018, de https://bndigital.bn.br/hemeroteca-digital/.

Rio de Janeiro (Estado). (1866a, janeiro 4). Miguel M. Jardim nomeado pensionista da Escola Normal. Correio Mercantil, XXIII(1). Retirado em 02 de fevereiro, 2018, de https://bndigital.bn.br/hemeroteca-digital/.

Rio de Janeiro (Estado). (1866b, dezembro 15). Miguel M. Jardim conclui o curso na Escola Normal em 1866. A Patria, XI(9). Retirado em 04 de fevereiro, 2018, de https://bndigital.bn.br/hemeroteca-digital/.

Rio de Janeiro (Estado). (1867, fevereiro 9). Nomeação de Miguel Maria Jardim para o cargo de professor público efetivo do Rio de Janeiro. Diário do Rio de Janeiro, XLVII(35). Retirado em 03 de fevereiro, 2018, de https://bndigital.bn.br/hemeroteca-digital/.

Rio de Janeiro (Estado). (1868, dezembro 15). Remoção de Miguel M. Jardim para Ponta de Aréa. Diário do Rio de Janeiro, 51(343). Retirado em 03 de fevereiro, 2018, de https://bndigital.bn.br/hemeroteca-digital/. 
DOI: http://dx.doi.org/10.20396/zet.v27i0.8654287

Rio de Janeiro (Estado). (1872a, junho 23). Miguel M. Jardim - professor passa ser professor vitalício na Instrução Pública do Rio de Janeiro em 1872. A Patria, XIV(112). Retirado em (colocar a data), de https://bndigital.bn.br/hemeroteca-digital/.

Rio de Janeiro (Estado). (1872b, julho 14). Remoção de Miguel Maria Jardim para São Domingos. A Instrucção Publica: Publicação Hebdomadaria, I(14).Retirado em 03 de fevereiro, 2018, de https://bndigital.bn.br/hemeroteca-digital/.

Rio de Janeiro (Estado). (1872c, julho 21). Taboada Métrica de Jardim. A Instrucção Publica: Publicação Hebdomadaria, I(15). Retirado em 12 de maio, 2018, de https://bndigital.bn.br/hemeroteca-digital/.

Rio de Janeiro (Estado). (1872d, novembro 6). Arithmetica Elementar de Jardim pública em 1872. A Reforma, IV(256). Retirado em 04 de fevereiro, 2018, de https://bndigital.bn.br/hemeroteca-digital/.

Rio de Janeiro (Estado). (1873a, agosto 24). Estatuto do Instituto Pedagogico da Província do Rio de Janeiro. A Instrucção Publica: Publicação Hebdomadaria, II(34). Retirado em 12 de março, 2018, de https://bndigital.bn.br/hemeroteca-digital/.

Rio de Janeiro (Estado). (1873b, agosto 24). Professores filiados ao Instituto Pedagogico da Província do Rio de Janeiro. A Instrucção Publica: Publicação Hebdomadaria, II(46). Retirado em 12 de março, 2018, de https://bndigital.bn.br/hemeroteca-digital/.

Rio de Janeiro (Estado). (1875, março 24). Arithmetica Elementar de Jardim é adotada pela Instrução Pública da Província do Rio de Janeiro em 1875. O Globo, II (82). Retirado em 10 de fevereiro, 2018, de bndigital.bn.br/hemeroteca-digital/.

Rio de Janeiro (Estado). (1877). Miguel M. Jardim recebe o título de sócio honorário do Instituto Pedagógico de São Paulo em 1877. A Escola: Revista Brasileira de Educação e Ensino, II. Retirado em 06 de fevereiro, 2018, de https://bndigital.bn.br/hemerotecadigital/.

Rio de Janeiro (Estado). (1878). Annaes da Assembleia Legislatia Provincial do Rio de Janeiro. Miguel Maria Jardim licenciado, em 09 de outubro de 1878. Rio de Janeiro: Typographia Imperial e C. de J. Villeneuve \& C. Retirado em 02 de fevereiro, 2018, de https://bndigital.bn.br/hemeroteca-digital/.

Rio de Janeiro (Estado). (1879, dezembro 14). Miguel M. Jardim retorna da Europa em 1879. $O$ Fluminense, II(250). Retirado em 15 de fevereiro, 2018, de https://bndigital.bn.br/hemeroteca-digital/.

Rio de Janeiro (Estado). (1880, dezembro 24). Tempo de serviço de Miguel Maria Jardim na Instrução Pública do Rio de Janeiro. O Fluminense, III(409). Retirado em 08 de fevereiro, 2018, de https://bndigital.bn.br/hemeroteca-digital/.

Rio de Janeiro (Estado). (1885, outubro 9). Miguel M. Jardim nomeado inspetor das escolas de Niterói em 1885. O Fluminense, VIII(1.122). Retirado em 12 de junho, 2018, de https://bndigital.bn.br/hemeroteca-digital/.

Rio de Janeiro (Estado). (1895a, março 9). Morre a esposa de Miguel Maria Jardim. $O$ Fluminense, XVIII(2.680). Retirado em 07 de junho, 2018, de https://bndigital.bn.br/hemeroteca-digital/. 
DOI: http://dx.doi.org/10.20396/zet.v27i0.8654287

Rio de Janeiro (Estado). (1895b, dezembro 15). Miguel M. Jardim solicita exoneração do cargo de delegado de instrução da cidade de Niterói em 1895. O Fluminense, XVIII (2.922). Retirado em 12 de junho, 2018, de https://bndigital.bn.br/hemeroteca-digital/.

Rio de Janeiro (Estado). (1899a, fevereiro 11). Nova Arithmetica de Jardim publicada em 1899. $O$ Fluminense, XXII(3.876). Retirado em 07 de junho, 2018, de https://bndigital.bn.br/hemeroteca-digital/.

Rio de Janeiro (Estado). (1899b, junho 7). Nova Arithmetica de Jardim publicada em 1899. $O$ Fluminense, XXII(3.973). Retirado em 07 de junho, 2018, de https://bndigital.bn.br/hemeroteca-digital/.

Rio de Janeiro (Estado). (1907, setembro 6). Arithmetica Elementar de Jardim é adotada nas Escolas de Aprendizes Marinheiros. Gazeta de Notícias, XXIII(249). Retirado em 01 de dezembro, 2018, de https://bndigital.bn.br/hemeroteca-digital/.

Rio de Janeiro (Estado). (1917). Livraria Miguel Maria Jardim. Almanak Laemmert: Administrativo, Mercantil, 73(2). Retirado em 04 de fevereiro, 2018, de https://bndigital.bn.br/hemeroteca-digital/.

Rio de Janeiro (Estado). (1925a, dezembro 2). Miguel M. Jardim atuou como jornalista. $O$ Fluminense, 48(13.079). Retirado em 07 de fevereiro, 2018, de https://bndigital.bn.br/hemeroteca-digital/.

Rio de Janeiro (Estado). (1925b, dezembro 5). Nota de falecimento de Miguel M. Jardim. Correio da Manhã, XXV(9.467). Retirado em 17 de fevereiro, 2018, de /https://bndigital.bn.br/hemeroteca-digital/.

São Paulo (Estado). (1873a, fevereiro 19). Arithmetica Elementar de Miguel M. Jardim tem a 2. ${ }^{a}$ edição divulgada em São Paulo em 1873. Diário de São Paulo, VIII(2.201). Retirado em 17 de maio, 2018, de https://bndigital.bn.br/hemeroteca-digital/.

São Paulo (Estado). (1873b, fevereiro 27). Arithmetica Elementar de Miguel M. Jardim tem a $2^{a}$ edição divulgada em São Paulo em 1873. Gazeta de Campinas, IV(335). Retirado em 17 de maio, 2018, de https://bndigital.bn.br/hemeroteca-digital/.

São Paulo (Estado). (1877, março 8). Professores paulistas solicitam adoção da Arithmetica de Jardim junto ao governo em 1877. Diário de São Paulo, XII(3.368). Retirado em 10 de fevereiro, 2018, de https://bndigital.bn.br/hemeroteca-digital/.

São Paulo (Estado). (1882, agosto 11). Nova Arithmetica de Jardim publicada em 1882. Correio Paulistano, XXIX(7.738). Retirado em 06 de junho, 2018, de https://bndigital.bn.br/hemeroteca-digital/.

Siqueira Filho, M. G. (2016). A Matemática na formação de professores primários no Espírito Santo (1890-1908). Revista Diálogo Educação, 16(48), 365-380.

Villela, H. O. S. (2002). O mestre-escola e a professora. In E. M. T. Lopes, L. M. Faria Filho \& C. G. Veiga (Orgs.), 500 Anos de Educação no Brasil (pp. 95-134). Belo Horizonte: Autêntica.

Villela, H. O. S. (2008). A primeira escola normal do Brasil: concepções sobre a institucionalização da formação docente no século XIX. In J. C. Araujo, A. M. B. Freitas \& A. P. C. Lopes (Orgs.), As escolas normais no Brasil: do Império à República (pp. 2945). Campinas: Alínea. 